\title{
Changes in the Ultrastructures of the Coral Pocillopora damicornis after Exposure to High Temperature, Ultraviolet and Far-Red Radiation
}

\author{
Alex Pulvinar Camaya ${ }^{1,2 *}$, Satoko Sekida ${ }^{1}$ and Kazuo Okuda ${ }^{1}$ \\ ${ }^{1}$ Graduate School of Kuroshio Science, Kochi University, 2-5-1 Akebono-cho, Kochi 780-8520, Japan \\ ${ }^{2}$ Coastal Resource Management Unit, Bicol University Tabaco Campus, Albay 4511, Philippines
}

Received April 20, 2016; accepted October 5, 2016

\begin{abstract}
Summary Ultrastructural changes in the coral tissues and symbiotic zooxanthellae of the scleractinian coral, Pocillopora damicornis, after exposure to high temperature (HT), ultraviolet (UV) and far-red (FR) radiation were examined by transmission electron microscopy. In normal environmental conditions, the coral gastrodermis contained zero to two zooxanthellae and maintained well-defined cortical and intracellular structures. When corals were exposed to HT, UV and FR, the gastrodermal features changed remarkably depending on the duration of exposure. Treatment with HT for $15 \mathrm{~min}$ or exposure to UV and FR for $6 \mathrm{~h}$ induced the appearance of numerous, small, electron-dense granules in the gastrodermis. Autophagosomes and lysosomes in the gastrodermal cells also increased in number. The gastrodermal cells containing no zooxanthellae began to degrade and became vacuolated through the destruction and fragmentation of their cytoplasmic contents. Prolonged exposure to these stressors brought about the disintegration of the cells without zooxanthellae and led to the collapse of the gastrodermis. This resulted in the release of the other gastrodermal cells containing zooxanthellae from the gastrodermis to gastrovascular cavities. HT, UV and FR affected the gastrodermal cells without zooxanthellae more severely than the zooxanthellae themselves, although the thylakoids of the zooxanthellae were often destroyed when the coral was exposed to UV and FR. These results suggest that the coral receives the distinct stressors, HT, UV and FR, but has a common mechanism that promotes autolysis activities in the gastrodermis and discharges cells containing zooxanthellae.
\end{abstract}

Key words Autolysis, Coral, Environmental stress, Symbiosis breakdown, Ultrastructure, Zooxanthella.

Reef-building corals contain large populations of symbiotic dinoflagellate algae of the genus Symbiodinium, commonly referred to as zooxanthellae, and are fragile marine organisms which are vulnerable to natural disturbances (Birkeland 1997). Coccoid zooxanthellae in situ are located within the cells of the host gastrodermis (Trench 1993), and are bound by a membrane complex consisting of a series of membranes of algal origin and an outermost host-derived membrane. This entire entity is referred to as the symbiosome (Wakefield et al. 2000).

The loss of symbiotic algae from coral host tissues, which eventually leads to indiscriminate coral bleaching, is driven by various stress factors such as an increase in temperature and irradiance level, lowered $\mathrm{pH}$, and salinity changes (Goreau 1964, Glynn 1993, Hoegh-Guldberg 1999, Fitt et al. 2001, Anthony et al. 2008, Delgadillo-Nuño et al. 2014). High temperature conditions damage various intracellular components of zooxanthellae (Brown 1997, Hoegh-Guldberg 1999), and the effects of high temperature are promoted synergistically by intense light (Weis 2008). Chloroplasts

\footnotetext{
* Corresponding author, e-mail: 1hex3479@gmail.com DOI: $10.1508 /$ cytologia. 81.465
}

are one organelle that is remarkably affected by these stresses (Downs et al. 2002, Weis et al. 2008). When corals are exposed to high temperature or intense light irradiance, stress-induced products with oxidative activities can be formed in the chloroplasts of zooxanthellae and may trigger the expulsion of zooxanthellae from the coral host (Lesser 1997, Nii and Muscatine 1997, Downs et al. 2002, 2009, 2013, Franklin et al. 2004, Lesser and Farrell 2004, Smith et al. 2005). However, the mechanisms by which coral bleaching occurs in tissues and at the cellular level remain unclear (Downs et al. 2002, Weis et al. 2008). In addition, high irradiance to red light (Kinzie III et al. 1984, Kinzie III and Hunter 1987, Wijgerde et al. 2014) and exposure to ultraviolet radiation (Lesser and Shick 1990, Gleason and Wellington 1993, Shick et al. 1996) significantly decrease both coral growth and zooxanthellae density. It had been poorly understood how these stressors induce coral degradation, especially in the early stage of exposure.

The loss of symbiotic algae is associated with cellular degradation. Cell necrosis is known to be a considerable deleterious stress response of corals and causes the widespread detachment and rupturing of many cells throughout coral tissues (Dunn et al. 2000). Coral 
necrosis involves autolysis, where digestive enzymes may be produced to degrade cells (Müller et al. 1984). It has been reported that the degradation of host cells is caused by autophagy, which plays a role in digesting the engulfed cytoplasmic constituents and other materials (Dunn et al. 2007, Dunn and Weis 2009, Hanes and Kempf 2013). Other factors that bring about host cell degradation include programmed cell death (PCD), or apoptosis (Dunn et al. 2000, 2002, Dunn and Weis 2009, David et al. 2005, Paxton et al. 2013), pathogenic bacteria (Ben-Haim et al. 2003), or viral infection (Lohr et al. 2007). It is unknown if these distinct factors mutually influence coral host cells or how various environmental stresses promote digestive activities in coral cells (Fitt et al. 2001, Downs et al. 2009).

In this study, the hermatypic coral Pocillopora damicornis (Linnaeus) was experimentally exposed to three distinct stressors: high temperature (HT), ultraviolet (UV) and far-red (FR) radiation. We examined the changes in the ultrastructure of the host cells and symbiotic zooxanthellae under these stress conditions.

\section{Materials and methods}

Colonies of $P$. damicornis were collected from shallow water (1-3 $\mathrm{m}$ in depth) off the Yokonami Peninsula facing Tosa Bay, Susaki City, Kochi Prefecture in Japan, from June to October 2014. After collection, they were then transported to Kochi University in Kochi City $1 \mathrm{~h}$ by car. Apical segments $2-3 \mathrm{~cm}$ in length were excised from the colony branches, transferred to Petri dishes containing approximately $50 \mathrm{~mL}$ of filtered natural seawater and placed under ambient light and room temperature at 25 to $27^{\circ} \mathrm{C}$ before use. Colonies of these segments relaxed with extending tentacles two to three days after collection and lived normally for at least a month under these conditions. These coral segments were precultured for a week before experiments in Petri dishes containing filtered seawater at $25^{\circ} \mathrm{C}$ under long-day conditions (14h light: $10 \mathrm{~h}$ dark cycle) created by cool white fluorescent lamps with an intensity of 10-20 $\mu$ molphotons $\mathrm{m}^{-2} \mathrm{~s}^{-1}$.

For HT treatments, Petri dishes in which live coral segments were maintained in filtered seawater were soaked in a water bath maintained at $32^{\circ} \mathrm{C}$ by a heater (Thermo-mate BF-21; Yamato Scientific Co., Ltd., Tokyo, Japan). Samples were treated with HT at $32^{\circ} \mathrm{C}$ for 15, 30, 60 and $120 \mathrm{~min}$ and then fixed. For UV and FR treatments, LED light units (IS-mini series; CCS Inc., Tokyo, Japan) were used. Samples in Petri dishes containing filtered seawater were exposed to UV-A with a peak wavelength of $405 \mathrm{~nm}$ at an intensity of $4.5 \mathrm{~W} \mathrm{~m}^{-2}$ for $6,12,30$ and $48 \mathrm{~h}$ and then fixed. Similarly, samples were exposed to FR with a peak wavelength of $735 \mathrm{~nm}$ at $2.0 \mathrm{~W} \mathrm{~m}^{-2}$ for $6,12,30$ and $48 \mathrm{~h}$ and then fixed. The control treatment was maintained under the original ambi- ent light and temperature. These samples were observed under a dissecting microscope (SZX7; Olympus Optical Co., Ltd., Tokyo, Japan) with a digital camera (Coolpix P6000; Nikon Co., Ltd., Tokyo, Japan) at intervals of $10 \mathrm{~min}$ or $3 \mathrm{~h}$.

Some control samples were fixed chemically by the same procedures as samples exposed to HT, UV and FR (see below). The others were fixed using freezesubstitution methods. To avoid the retraction of polyps, colonies were anesthetized by adding $\mathrm{MgCl}_{2}$ solution to the seawater medium (Janes 2008). Polyps were excised by dissecting scissors and then rapidly frozen in a highpressure freezer (HPM100; Leica Microsystems, Wetzlar, Germany). The frozen specimens were transferred to acetone containing $1 \%$ osmium tetroxide at $-80^{\circ} \mathrm{C}$ and stored in a deep freezer at $-80^{\circ} \mathrm{C}$ for $72 \mathrm{~h}$. Subsequently, samples were placed in $-20^{\circ} \mathrm{C}$ for $24 \mathrm{~h}$, held at $4^{\circ} \mathrm{C}$ overnight and then warmed to room temperature. They were rinsed with dry acetone five times, fragmented into small pieces using a fine razor, infiltrated with a mixture of dry acetone and Spurr's resin, and finally embedded in Spurr's resin.

Since colony tentacles retracted immediately after they were exposed to HT, UV and FR, it was difficult to fix them by freeze-substitution procedures. Therefore, chemical fixation was adopted for the samples exposed to these stressors. Whole colony segments were immersed in a fixative containing $4 \%$ paraformaldehyde, $2 \%$ glutaraldehyde and $0.1 \mathrm{M}$ sucrose dissolved in $0.1 \mathrm{M}$ phosphate buffer ( $\mathrm{pH} 7.2$ ) for $2 \mathrm{~h}$ at room temperature and stored for $48 \mathrm{~h}$ at $5^{\circ} \mathrm{C}$. Fixed colonies were decalcified in $5 \%$ ethylenediamine- $N, N, N^{\prime}, N^{\prime}$-tetraacetic acid (pH 7.2) containing 0.2 M sucrose (Kurahashi 1965) for four to five days. Decalcified colony samples were rinsed with $0.1 \mathrm{M}$ phosphate buffer containing $0.1 \mathrm{M}$ sucrose five times, cut into several pieces with a fine razor and then post-fixed in $0.1 \mathrm{M}$ phosphate buffer ( $\mathrm{pH} 7.2$ ) containing $1 \% \mathrm{KMnO}_{4}$ and $0.1 \mathrm{M}$ sucrose for $30 \mathrm{~min}$ at $5^{\circ} \mathrm{C}$. Post-fixed specimens were rinsed with the buffer, dehydrated in an acetone series for $2.5 \mathrm{~h}$ and embedded in Spurr's resin. Thin sections were made using a diamond knife on a Leica Utracut UCT ultramicrotome (Leica Microsystems) and stained with 1\% uranyl acetate followed by lead citrate. They were then examined with a JEOL JEM-1400 electron microscope (JEOL Co., Ltd., Tokyo, Japan).

The number of autophagosomes and lysosomes found in the gastrodermal cells were counted on thin sections. At least 100 sectioned cells of gastrodermis were observed and examined for how many autophagosomes and lysosomes were situated in the individual cells for both the control treatment and the samples that were exposed to HT, UV and FR for each different exposure interval. 
Results

\section{Control}

Coral tissues in the control treatment showed a body pattern typical of diploblastic organisms and consisted of two layers, the epidermis and gastrodermis, interconnected by an acellular matrix mesoglea (Fig. 1a). Some cells of the gastrodermis harbored one to two symbiotic zooxanthellae, whereas the others contained no zooxanthellae. Each symbiotic zooxanthella had peripheral chloroplasts with a pyrenoid, a mesokaryotic nucleus and other organelles (Fig. 1b). The cortical region of the cell was composed of the outermost plasma membrane and a layer of flattened amphiesmal vesicles with underlying cortical microtubules (Fig. 1c). The entire symbiotic zooxanthella cell was enclosed by a symbiosome membrane in the host gastrodermal cell. There were stacks of membranous fragments between the plasma membrane of the zooxanthella and the symbiosome membrane. In some gastrodermal cells, small, darkstained lysosomes and another type of membrane structure were observed (Fig. 1d). The latter was initially a cup-shaped double-membrane sac, which later expanded in size, and its open end eventually closed to form a double-membrane vesicle. This is referred to as an autophagosome in this study. Autophagosomes contained several distinct inclusions (Fig. 1d). The average densities of lysosomes and autophagosomes observed on a sectioned gastrodermal cell were 1.55 and 0.66 , respectively.

\section{Effect of $H T$}

When corals were exposed to HT for $15 \mathrm{~min}$, several electron-dense granules appeared in the cytoplasm of the cells without zooxanthellae (Fig. 2a). These dense granules were regarded as lysosomes. The average number of autophagosomes contained in a sectioned gastrodermal cell was 2.3 for that exposure interval. Exposure to HT for 30-60 min caused severe vacuolization of the cells without zooxanthellae, followed by the dispersal of their cellular contents (Fig. 2b). This disintegrated the gastrodermis, and thus the cells containing zooxanthellae detached from the gastrodermis and were released into gastrovascular cavities (Fig. 2c). Under the dissecting microscope, particles of zooxanthellae in situ began to wiggle within the coral tissues and were suspended in gastrovascular cavities $90 \mathrm{~min}$ and $2 \mathrm{~h}$ after the initial HT exposure, respectively (data not shown).

\section{Effect of $U V$}

After corals were exposed to UV for $6 \mathrm{~h}$, autophagosomes increased in size and number and contained distinct inclusions (Fig. 2d). The average number of autophagosomes per sectioned gastrodermal cells was 1.6 and 2.7 after exposure to UV for 12 and $48 \mathrm{~h}$, respective-

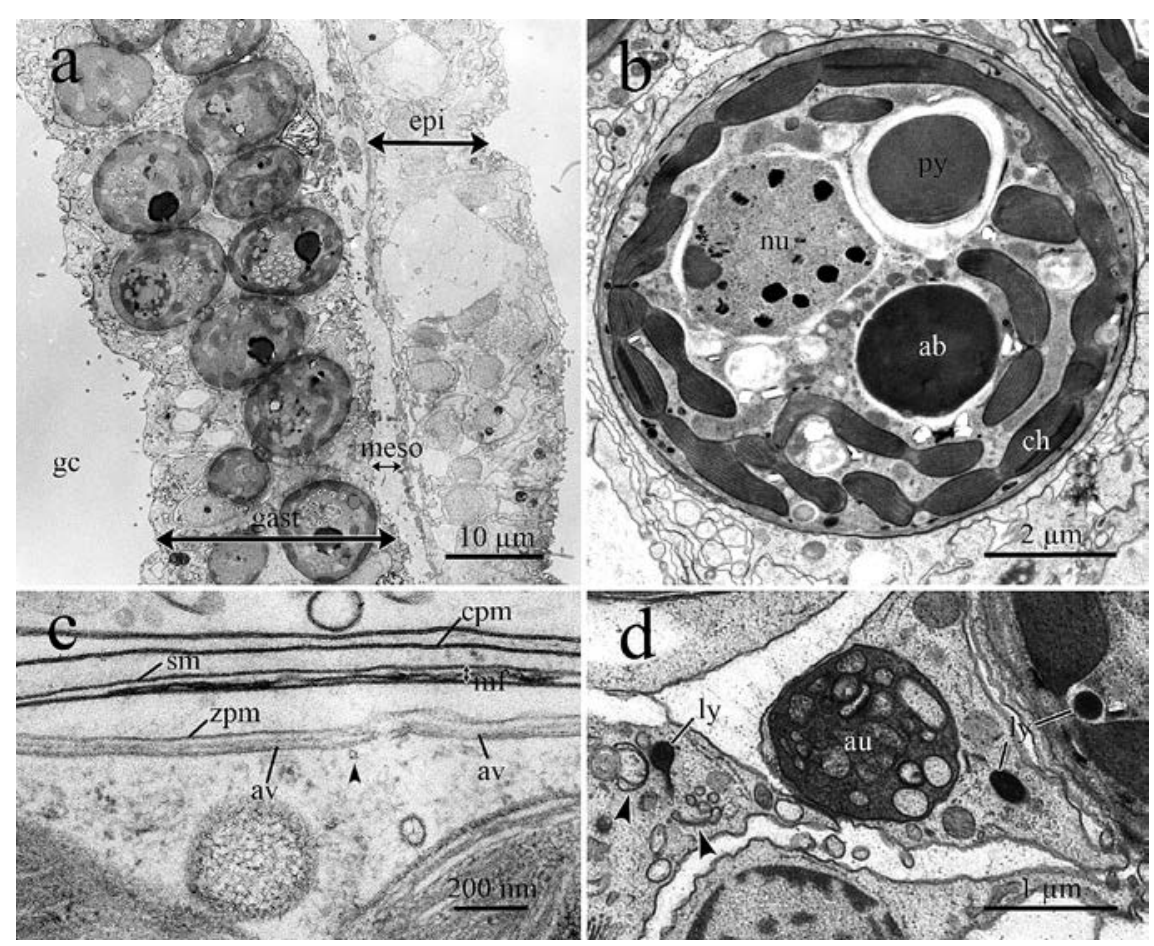

Fig. 1. Electron micrographs of Pocillopora damicornis in control. Samples were made through chemical fixation (a) and freezesubstitution $(b-d)$. a. Longitudinal section of a tentacle showing the two layers of epidermis (epi) and gastrodermis (gast) interconnected by the mesoglea (meso). gc, gastrovascular cavity. b. Symbiotic zooxanthella occupying the large space of a gastrodermal host cell. nu, nucleus; py, pyrenoid; ab, accumulation body; ch, chloroplast. c. Cortical structure of a symbiotic zooxanthella. av, amphiesmal vesicle; zpm, the plasma membrane of the zooxanthella; mf, membranous fragments; sm, symbiosome membrane; cpm, the plasma membrane of the coral host cell. d. Autophagosome (au) and lysosomes (ly) found in the gastrodermis. Arrows showing cup-shaped double membrane sacs. 


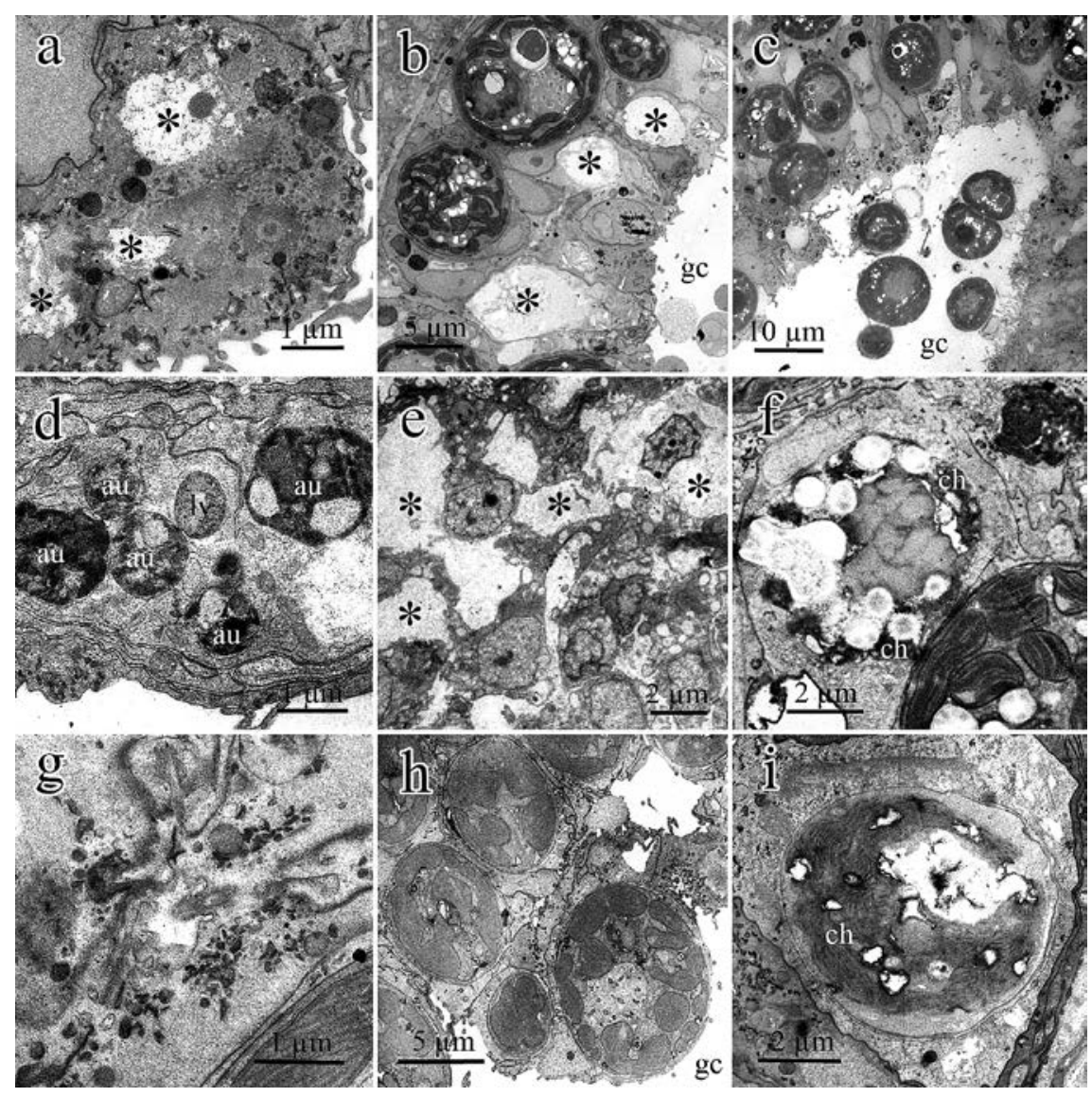

Fig. 2. Electron micrographs of Pocillopora damicornis exposed to HT (a-c), UV (d-f) and FR (g-i). a. Electron dense granules and vacuolated areas (asterisks) in gastrodermal cells without zooxanthellae after exposure to HT for $15 \mathrm{~min}$. b. Cells without zooxanthellae that were vacuolated and almost lost their cytoplasm (asterisks) after exposure to HT for $1 \mathrm{~h}$. gc, gastrvascular cavity. c. Gastrodermal cells with zooxanthellae released from gastrodermis to gastrovascular cavity (gc). d. Autophagosomes (au) and lysosomes (ly) in gastrodermal cells without zooxanthellae after exposure to UV for $6 \mathrm{~h}$. e. Degenerating cells without zooxanthellae showing the occurrence of vacuolated areas (asterisks) after exposure to UV for $12 \mathrm{~h}$. f. A zooxanthella whose cytoplasmic components were destroyed after exposure to UV for $12 \mathrm{~h}$. ch, chloroplast. g. Many lysosomes distributed in cells without zooxanthellae after exposure to FR for $6 \mathrm{~h}$. h. Cells with zooxanthellae just before detaching from the gastrodermis after exposure to FR for $30 \mathrm{~h}$. i. A degenerated zooxanthella after exposure to FR for $30 \mathrm{~h}$. ch, chloroplast.

ly. The cells without zooxanthellae became vacuolated and disconnected from the adjacent cells $12 \mathrm{~h}$ after the initial UV exposure (Fig. 2e). Such disorganization of the gastrodermis led the cells containing zooxanthellae to detach from the gastrodermis after exposure to $\mathrm{UV}$ for $30 \mathrm{~h}$ and $48 \mathrm{~h}$. Under in situ observation by light microscopy, zooxanthella particles wiggled in the coral coenenchyme and floated in gastrovascular cavities 12 and $30 \mathrm{~h}$ after the initial UV exposure, respectively (data not shown). Degradation of intracellular components occurred not only in the gastrodermis, but also in symbiotic zooxanthellae (Fig. 2f). The cytoplasm of zooxanthellae was vacuolated in places, and the chloroplasts were often destroyed completely, leaving dark amorphous materials.

\section{Effect of FR}

When corals were exposed to FR for $6 \mathrm{~h}$, a number of small lysosomes appeared in the cytoplasm of the gastrodermal cells (Fig. 2g). The average number of au- tophagosomes per sectioned gastrodermal cell became 1.5 and 2.6 after exposure to FR for 12 and $48 \mathrm{~h}$, respectively. The cells without zooxanthellae became amorphous and began to degenerate. Such degenerated cells increased in number concomitantly with an increase in the duration of FR exposure. Exposure to FR for $12 \mathrm{~h}$ induced the wiggling movement of zooxanthella particles in situ (data not shown). When zooxanthella particles in situ were expelled from the coenenchyme and floated in gastrovascular cavities 30 and $48 \mathrm{~h}$ after the initial FR exposure, we observed via electron microscopy that the cells containing zooxanthellae were detached from the gastrodermis (Fig. 2h). Exposure to FR also affected the structure of symbiotic zooxanthellae, including the disruption of the zooxanthella cytoplasmic contents and thylakoid membranes of the chloroplasts (Fig. 2i).

\section{Discussion}

Through the use of transmission electron micros- 
copy, this study has demonstrated that in the coral $P$. damicornis, exposure to HT, UV and FR destroys the organization of the coral gastrodermis. Early ultrastructural changes were noticed in the gastrodermal cells without symbiotic zooxanthellae after the initial exposure to these stressors. The number of lysosomes and autophagosomes increased in the cells. Longer exposure to the stressors led to the vacuolation and fragmentation of the cytoplasm, resulting in the breakdown of the cells. Patterns of cellular degradation occurring in the gastrodermal cells when the coral was exposed to these stressors may be characterized as necrosis. Dunn et al. $(2000,2002)$ have reported that autolytic digestion of cytoplasm in coral host cells occurs through necrosis under stressful conditions. In addition to necrosis, it has been reported that autophagic activities degrade coral host cells in response to stress conditions (Hanes and Kempf 2013). The degradation of host cells is triggered by the appearance of autophagosomes or autophagolysosomes (Hanes and Kempf 2013), where cytoplasmic components are engulfed and digested by autophagosomes (Shibutani and Yoshimori 2014). These reports suggest that the vacuolation and fragmentation of the gastrodermal cells of $P$. damicornis under stress conditions are due to necrosis and autophagy. This study showed that in even control conditions without any stresses, gastrodermal cells had autophagosomes in $P$. damicornis. In this case, autophagosomes seemed to selectively degrade cytoplasmic components as normal metabolism in the cells. Once the coral was placed in stress conditions, autophagosomes in the gastrodermis increased and digested the cells they were present in. These facts suggest that in P. damicornis, stress factors such as HT, UV and FR might induce autophagosomes to lose the specificity where targets to degrade are selective.

In this study, prolonged exposure to HT, UV and FR caused the cells containing zooxanthellae to be discharged from the gastrodermis. In the control treatment, adjacent cells in the gastrodermis were tightly connected with each other. Since the gastrodermal cells without zooxanthellae collapsed under stress conditions, it is plausible that cell-to-cell adhesion in the gastrodermis weakened, the gastrodermis became disorganized, and eventually the cells containing zooxanthellae were expelled from the gastrodermis.

Symbiotic zooxanthellae are known to generate reactive oxygen species (ROS) under UV radiation and high temperature conditions (Lesser et al. 1990, Lesser 1997, Nii and Muscatine 1997). ROS oxidize membrane lipids and make proteins and nucleic acids to denature and damage thylakoids in chloroplasts (Smith et al. 2005). However, Downs et al. $(2009,2013)$ have reported that oxidative stress substances may be produced mainly by coral host cells. In this study, chloroplasts and other cellular components in some zooxanthellae were disrupted by exposure to UV and FR. Symbiotic zooxanthellae in
$P$. damicornis might be susceptible to UV and FR more than HT. However, even short exposure to HT damaged the coral gastrodermis more severely than in UV or FR. Three different stressors, HT, UV and FR, brought about the degradation of gastrodermal cells without zooxanthellae, so that the gastrodermal cells containing zooxanthellae were released from the gastrodermis. This suggests that the coral may receive distinct stress factors, but has a common mechanism by which the gastrodermal cells without zooxanthellae are selectively digested.

\section{Acknowledgements}

We thank Dr. Yohei Nakamura, Graduate School of Kuroshio Science, Kochi University, for helping us to collect living coral samples.

\section{References}

Anthony, K. R. N., Kline, D. I., Diaz-Pulido, G., Dove, S. and HoeghGuldberg, O. 2008. Ocean acidification causes bleaching and productivity loss in coral reef builders. Proc. Natl. Acad. Sci. U.S.A. 105: 17442-17446.

Ben-Haim, Y., Zicherman-Keren, M. and Rosenberg, E. 2003. Temperature-regulated bleaching and lysis of the coral Pocillopora damicornis by the novel pathogen Vibrio coralliilyticus. Appl. Environ. Microbiol. 69: 4236-4242.

Birkeland, C. 1997. Life and Death of Coral Reefs. Chapman \& Hall, New York.

Brown, B. E. 1997. Coral bleaching: Causes and consequences. Coral Reefs 16: S129-S138.

David, C. N., Schmidt, N., Schade, M., Pauly, B., Alexandrova, O. and Böttger, A. 2005. Hydra and the evolution of apoptosis. Integr. Comp. Biol. 45: 631-638.

Delgadillo-Nuño, M. A., Liñan-Cabello, M. A., Reyes-Gomez, J. and Soriano-Santiago, O. 2014. Response to $\mathrm{pH}$ stress in the reefbuilding coral Pocilliopora capitata (Anthozoa: Scleractinia). Rev. Biol. Mar. Oceanogr. 49: 449-459.

Downs, C. A., Fauth, J. E., Halas, J. C., Dustan, P., Bemiss, J. and Woodley, C. M. 2002. Oxidative stress and seasonal coral bleaching. Free Radic. Biol. Med. 33: 533-543.

Downs, C. A., Kramarsky-Winter, E., Martinez, J., Kushmaro, A., Woodley, C. M., Loya, Y. and Ostrander, G. K. 2009. Symbiophagy as a cellular mechanism for coral bleaching. Autophagy 5: $211-216$.

Downs, C. A., McDougall, K. E., Woodley, C. M., Fauth, J. E., Richmond, R. H., Kushmaro, A., Gibb, S. W., Loya, Y., Ostrander, G. K. and Kramarsky-Winter, E. 2013. Heat-stress and light-stress induce different cellular pathologies in the symbiotic dinoflagellate during coral bleaching. PLoS ONE 8: e77173.

Dunn, S. R., Bythell, J. C., Le Tissier, M. D. A., Burnett, W. J. and Thomason, J. C. 2002. Programmed cell death and cell necrosis activity during hyperthermic stress-induced bleaching of the symbiotic sea anemone Aiptasia sp. J. Exp. Mar. Biol. Ecol. 272: 29-53.

Dunn, S. R., Schnitzler, C. E. and Weis, V. M. 2007. Apoptosis and autophagy as mechanisms of dinoflagellate symbiont release during cnidarian bleaching: Every which way you lose. Proc. R. Soc. B. 274: 3079-3085.

Dunn, S. R., Thomason, J. C., Le Tissier, M. D. A. and Bythell, J. C. 2000. Detection of cell death activity during experimentally 
induced bleaching of the symbiotic sea anemone Aiptasia sp. In: The 9th International Coral Reef Symposium, Bali. pp. 145-155.

Dunn, S. R. and Weis, V. M. 2009. Apoptosis as a post-phagocytic winnowing mechanism in a coral-dinoflagellate mutualism. Environ. Microbiol. 11: 268-276.

Fitt, W. K., Brown, B. E., Warner, M. E. and Dunne, R. P. 2001. Coral bleaching: Interpretation of thermal tolerance limits and thermal thresholds in tropical corals. Coral Reefs 20: 51-65.

Franklin, D. J., Hoegh-Guldberg, O., Jones, R. J. and Berges, J. A. 2004. Cell death and degeneration in the symbiotic dinoflagellates of the coral Stylophora pistillata during bleaching. Mar. Ecol. Prog. Ser. 272: 117-130.

Gleason, D. F. and Wellington, G. M. 1993. Ultraviolet radiation and coral bleaching. Nature 365: 836-838.

Glynn, P. W. 1993. Coral reef bleaching: Ecological perspectives. Coral Reefs 12: 1-17.

Goreau, T. F. 1964. Mass expulsion of zooxanthellae from Jamaican reef communities after hurricane Flora. Science 145: 383-386.

Hanes, S. D. and Kempf, S. C. 2013. Host autophagic degradation and associated symbiont loss in response to heat stress in the symbiotic anemone, Aiptasia pallida. Invertebr. Biol. 132: 95-107.

Hoegh-Guldberg, O. 1999. Climage change, coral bleaching and the future of the world's coral reefs. Mar. Freshw. Res. 50: 839-866.

Janes, M. P. 2008. Laboratory methods for the identification of soft corals (Octocorallia: Alcyonacea). In: Leewis, R. J. and Janse, M. (eds.). Advances in Coral Husbandry in Public Aquariums. Public Aquarium Husbandry Series, Vol. 2. Burgers' Zoo, Arnhem. pp. 413-426.

Kinzie, R. A. III and Hunter, T. 1987. Effect of light quality on photosynthesis of the reef coral Montipora verrucosa. Mar. Biol. 94: 95-109.

Kinzie, R. A. III, Jokiel, P. L. and York, R. 1984. Effects of light of altered spectral composition on coral zooxanthellae associations and on zooxanthellae in vitro. Mar. Biol. 78: 239-248.

Kurahashi, Y. 1965. Perfusion fixation with glutaraldehyde and its application for cytochemistry of developing teeth. J. Electron Microsc. 14: 337-338.

Lesser, M. P. 1997. Oxidative stress causes coral bleaching during exposure to elevated temperatures. Coral Reefs 16: 187-192.

Lesser, M. P. and Farrell, J. H. 2004. Exposure to solar radiation increases damage to both host tissues and algal symbionts of corals during thermal stress. Coral Reefs 23: 367-377.

Lesser, M. P. and Shick, J. M. 1990. Effects of visible and ultraviolet radiation on the ultrastructure of zooxanthellae (Symbiodinium sp.) in culture and in situ. Cell Tissue Res. 261: 501-508.

Lesser, M. P., Stochaj, W. R., Tapley, D. W. and Shick, J. M. 1990. Bleaching in coral reef anthozoans: Effects of irradiance, ultraviolet radiation, and temperature on the activities of protective enzymes against active oxygen. Coral Reefs 8: 225-232.

Lohr, J., Munn, C. B. and Wilson, W. H. 2007. Characterization of a latent virus-like infection of symbiotic zooxanthellae. Appl. Environ. Microbiol. 73: 2976-2981.

Müller, W. E. G., Müller, I., Zahn, R. K. and Maidhof, A. 1984. Intraspecific recognition system in scleractinian corals: Morphological and cytochemical description of the autolysis mechanism. J. Histochem. Cytochem. 32: 285-288.

Nii, C. M. and Muscatine, L. 1997. Oxidative stress in the symbiotic sea anemone Aiptasia pulchella (Carlgren, 1943): Contribution of the animal to superoxide ion production at elevated temperature. Biol. Bull. 192: 444-456.

Paxton, C. W., Davy, S. K. and Weis, V. M. 2013. Stress and death of cnidarian host cells play a role in cnidarian bleaching. J. Exp. Biol. 216: 2813-2820.

Shibutani, S. T. and Yoshimori, T. 2014. A current perspective of autophagosome biogenesis. Cell Res. 24: 58-68.

Shick, J. M., Lesser, M. P. and Jokiel, P. L. 1996. Effects of ultraviolet radiation on corals and other coral reef organisms. Glob. Change Biol. 2: 527-545.

Smith, D. J., Suggett, D. J. and Baker, N. R. 2005. Is photoinhibition of zooxanthellae photosynthesis the primary cause of thermal bleaching in corals? Glob. Change Biol. 11: 1-11.

Trench, R. K. 1993. Microalgal-invertebrate symbioses: A review. Endocytobiosis Cell Res. 9: 135-175.

Wakefield, T. S., Farmer, M. A. and Kempf, S. C. 2000. Revised description of the fine structure of in situ "zooxanthellae" genus Symbiodinium. Biol. Bull. 199: 76-84.

Weis, V. M. 2008. Cellular mechanisms of Cnidarian bleaching: Stress causes the collapse of symbiosis. J. Exp. Biol. 211: 30593066.

Weis, V. M., Davy, S. K., Hoegh-Guldberg, O., Rodriguez-Lanetty, M. and Pringle, J. R. 2008. Cell biology in model systems as the key to understand corals. Trends Ecol. Evol. 23: 369-376.

Wijgerde, T., van Melis, A., Silva, C. I. F., Leal, M. C., Vogels, L., Mutter, C. and Osinga, R. 2014. Red light represses the photophysiology of the scleractinian coral Stylophora pistillata. PLoS ONE 9: e92781. 